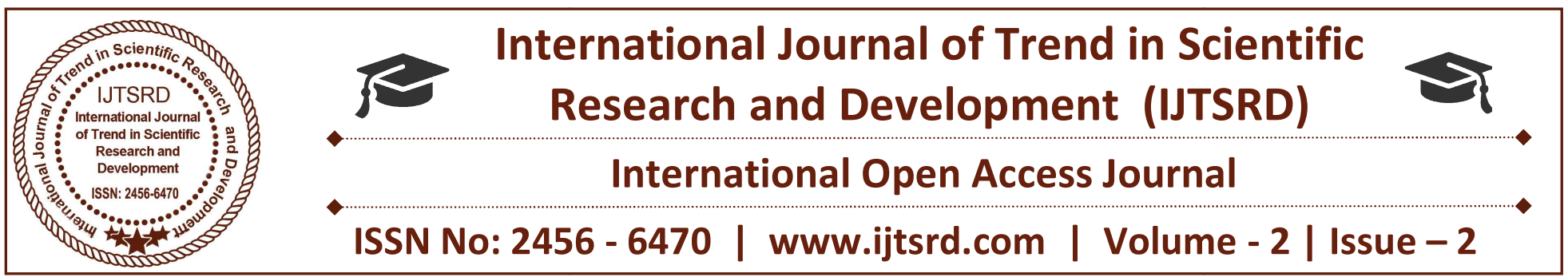

\title{
Cooling by using Earthen Pot
}

\author{
Rajat. R. Wade, Anurag. D. Choudhari \\ Student, Department of Mechanical Engineering, Jawaharlal Darda \\ Institute of Engineering \& Technology, Yavatmal, Maharashtra, India
}

\begin{abstract}
Demand for electric power is more in summer is concern for most utilities. However evaporating cooling required more amount of water which is main source as an evaporator, and this only work efficiently when humidity is low. Evaporating cooling could be a quite common kind of cooling for the thermal comfort since it is relative low cost and needed less energy than several different styles of cooling. In our project, we are using earthen pots and soft cotton curtains are used for cooled air. Meeting demand for electrical power throughout peak periods in the summer may be a major concern for many utilities within the fastmoving world. From the demand points of read on the grid and value to the consumer, need to quite know install, energy-efficient evaporative coolers instead of standard air conditioners.
\end{abstract}

Keywords: Cooling efficiency, desert cooler, earthenpots and thin cotton curtain

\section{INTRODUCTION}

The evaporating cooling has a better many advantages for cooling processes Economically every pad has large effective to a customary cause but testing results once analysis would verify the foremost effective material with relevancy performance. The literature reveals manufacturing of ordinary desert coolers expecting one entry for a recent desert cooler. The experiment results obtained up to currently once analysis would serve constant conditions for a recent desert cooler. This natural phase change cooling is otherwise cited as perspiration that secrets from body to chill down itself. The heat transfer from the body depends on the water evaporation rate of water. This rate of evaporation of water strictly depends on the temperature humidity of the air additional because of the pressure of the place. Hence, sweat accumulates plenty of on hot wet days throughout that the perspiration isn't potential to evaporate. Conventionally, earthen pot comprising of soft thin cotton curtain termed as packing. The thin cotton curtain which is in wet condition surrounded over an earthen pad, which is used to absorb the heat coming from atmosphere. Therefore, the circulation of cool air inside the refrigerator. Laboratory scale of experiment and arrangement for such were created and tested. The life span of earthen pot is more which gives the better performance of refrigerator. It is one of the healthiest way of cool our home because it is used clean air to replace the air in our home many times an hour.

\section{COMPONENTS:}

The components are used in this project are following below.

a) Earthen pot.

b) Desert cooler.

c) Frame.

d) Thin cotton curtain.

\section{a) Earthen pot:}

The walls of an earthen pot are porous, which ends up in oozing of water. it's the most reason you'll realize the surface wall wet. Currently the water that involves the surface although oozing gets gaseous. For evaporation to happen, there's an element known as heat of evaporation, i.e. it should absorb some heat to vary its material state from liquid to evaporated one. Therefore, it absorbs the warmth from the water 
within the pot to vary its state. Currently the water losing heat consequently loses temperature creating it cooler than the part temperature. And because of cooling effect we are using it. And the earthen pot is placed at the outer part of the desert cooler.

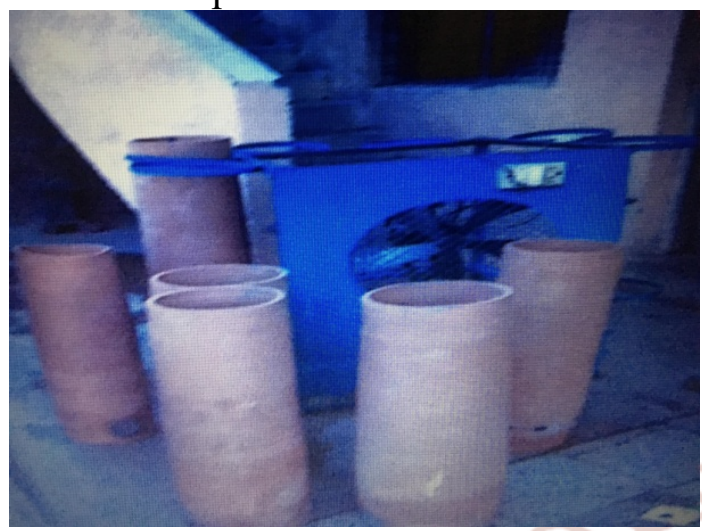

\section{b) Desert Cooler:}

A cooling (also swamp cooler, desert cooler and wet air cooler) could be a device that cools air through the evaporation of water. Phase change cooling differs from typical air-con systems that use vapourcompression or absorption refrigeration cycles. In our project, we tend to square measure victimization the stuff pot as pad. Means that the stuff pot contains the water. The temperature of dry air is born considerably through the physical change of liquid water to vapour (evaporation). This will cool air victimization a lot of less energy than refrigeration.

\section{c) Frame:}

The frame of the desert cooler as similar to simple cooler only the change is at the outer part of the desert cooler we are attached a circular ring for placing the earthen pot. The dimensions of the earthen pot are given the material description.

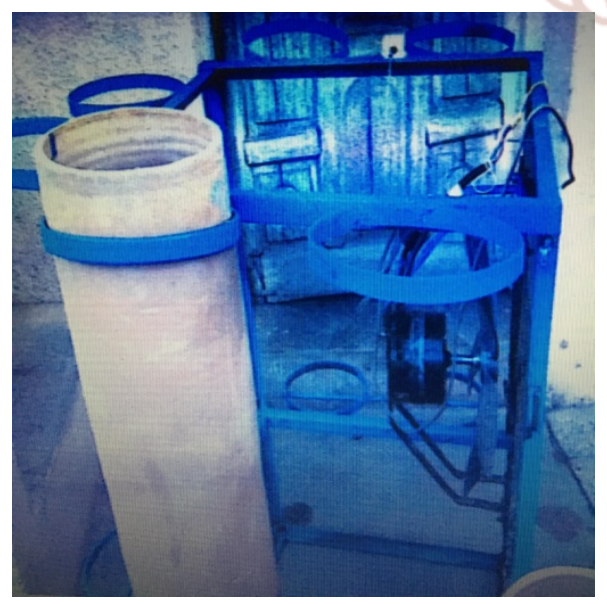

\section{d) Thin cotton curtain:}

We are victimisation the loincloth as thin cotton pad. This material pot is enclosed by the cotton pad. Because of that the air is coming back from outside is filtered then entered to fan. The most objects are containing the wet from the material pot that the new air coming back from the atmosphere is cooled by cotton pad then passes to the fan.

\section{MATERIAL DESCRIPTION:}

\section{COOLER:}

As the power input is only fan i.e. 180watt. All the calculation is as per "Indian standard evaporative air cooler (desert cooler)-specification (second revision)" DIMENSION OF COOLER:
a) Height $=0.90 \mathrm{~m}$
b) Breath $=0.50 \mathrm{~m}$
c) Width $=0.61 \mathrm{~m}$
d) Evaporation $=0.549 \mathrm{~m}^{2}+1.56 \mathrm{~m}^{2}$

\section{EARTHEN POT:}

\section{DIMENSION OF EARTHEN POTS:}
a) Height $=0.78 \mathrm{~m}$
b) Diameter $=0.17 \mathrm{~m}$ and $0.19 \mathrm{~m}$
c) Surface area $=3.062 \mathrm{~m}^{2}$
d) Surface area of pot $=0.427 \mathrm{~m}^{2} \& 0.477 \mathrm{~m}^{2}$
e) Area of exposure $=1.56 \mathrm{~m}^{2}$
f) Cubic capacity $=0.1371 \mathrm{~m}^{3}$

\section{FAN:}

Specification
a) $\mathrm{RPM}=1440 \mathrm{rpm}$
b) Phase $=1$
c) Power $=180$ watt, $230 \mathrm{v}, 50 \mathrm{hz} \mathrm{AC}$
d) Sweep $=0.30 \mathrm{~m}$
e) Discharge $=3064 \mathrm{~m} 3 / \mathrm{hr}$.

\section{WORKING PRINCIPAL:}

In this design, there is no need of pump which circulates water. A physical change air cooler isn't an air conditioning because it doesn't use a mechanical device and refrigerant gas. One shouldn't expect a physical change air cooler to figure as effectively as cold air-con. However, the benefits of the physical change air cooler over cold air-con. We are using earthen cylinder and porous material. There cylinders are connected to each other and continuous flow of water is attached to it with automatic arrangement of tap so that it will close when cylinder are full of 
water. The water in this cylinder will trickle and porous material will get wet. By the mean of evaporation air inside it will cool down and fan will make it flow. Generally ordinary cooler is only used for cooling purpose. In ordinary cooler tank, a provided at base of water is circulated from tank by submersible pump. This water is passed over the wood pulp. The wood pulps is placed over the 3 faces of the cooler. The wet wood pulp meets the air being sucked by the blower. This cool air is then supplied to the outer atmosphere by cooler. The last cylinder is provided with an outlet fitted with tap for drawing water from it.

As the cylinder is fitted with their water their outer surface becomes cool. When we switch on the blower atmosphere air is been sucked. This air meets the outer surface of the pipe thus becoming cool. This cool air is then released in the atmosphere by the blower. As the set of pipes is filled with water become cool by method of evaporation as in earthen pot. The cooling rate is much faster is this system as the inner surface of pipe continuously meet the cool air. This cool water can be taken for drinking purpose from the outlet. The air gets cooled by upcoming contact with the trickled water. This cool air circulates throughout the inner system as the blower is continuously rotating. This will decrease the temperature of inner system.

\section{CONCLUSION \& FUTURE SCOPE:}

In our day to day life the use of electricity is more but in summer its demand get increase. From this innovation of cooler help to saving electricity. The chosen material isearthen pot and thin cotton curtain. The performance criteria include cooling efficiency, air velocity and water consumption rate. Also, the life span of earthen pot is more than any other component. The thin cotton curtain is used to cool the air coming from the atmosphere. The minimum water consumption was found in earthen pot. The future scope of this project is to saving water and reduces the use of electric in summer. Evaporative cooling of water in a very little porous clay vessel was studied below controlled humidness conditions. In steadystate experiments performed at an ambient temperature of $23{ }^{\circ} \mathrm{C}$, the cooling effect increased from 4.7 to $8.3{ }^{\circ} \mathrm{C}$ as the ambient relative humidity decreased from 60 to $15 \%$. The main aim of our project is to save the water \& it's cost is also low. Therefore, the earthen pot and thin cotton curtain are used which reduces weight and increase cooling capacity of cooler.

\section{REFERANCE:}

1. Abdulla, K.N., Abdalla, A.M. and Al-Hashim, H.A. (1993). Utilization of Date Palm Leaves and Fibers as Wetted Pads in Evaporative Coolers.: Proceedings of the Third Symposium on the Date Palm, 2: 595- 601.

2. Bottcher, R.W., Baughman, G.R. and Kesler, D.J. (1989). Evaporative Cooling Using a Pneumatic Misting System. Transaction of the ASAE, 32, No. 2: 671-676.

3. B. Costelloe, D.P. Finn, (2005). Thermal efficiency characteristics of indirect evaporative cooling systems. International Conference Passive and Low Energy Cooling for the Built Environment: Santorini, Greece, pp.549-554.

4. Faleh Al-Sulaiman, (2002). Evaluation of the performance of local fibers in evaporative cooling. Energy Conversion and Management, Volume 43, Issue 16: pp. 2267-2273.

5. J.R.Camargo, (2008).Evaporative Cooling Water for Thermal Comfort. An Interdisciplinary Journal of Applied Science Vol 3, No4: pp.51-61

6. Koca, R.W., Hughes, W.C. and Christianson, L.L. (1991). Evaporative Cooling Pads Test Procedure and Evaluation. Applied Engineering in Agriculture, 7, No. 4: 485-490.

7. Mohammed A. Alodan and Abdulelah A. AlFara,. Design and Evaluation of Galvanized Metal Sheets as Evaporative Cooling Pads, J. King Saud Univ., Vol. 18, Agric. Sci. (1): pp. 9-18.

8. R. K. Kulkarni and S. P. S. Rajput, (2010). Theoretical performance analysis of jute fiber rope bank as media in evaporative coolers. Indian Journal of Science and Technology, Vol. 3 No. 10: pp 1075-1080

9. R. Rawangkul; J. Khedari; J. Hirunlabh; B. Zeghmati. (2008). Performance analysis of a new sustainable evaporative cooling pad made from coconut coir. International Journal of Sustainable Engineering, Volume 1, Issue 2: pp. 117 - 131. 